plot observed by Al-Sader ${ }^{10}$ for the symmetrical azoalkanes leads us to the conclusion that in the gas phase, azo compounds fragment into two species in the rate-determining step. This is best represented by eq 2 for azoalkanes, and is consistent with a similar conclusion obtained in the study of 1-pyrazolines. ${ }^{18}$

It is of particular interest to compare the activation energy obtained for $\mathbf{1}, \mathbf{2}$, and $\mathbf{4}$ with that of azoethane, ${ }^{19}$ $48.5 \mathrm{kcal} \mathrm{mol}^{-1}$. The decrease in activation energy, $12.4-13.0 \mathrm{kcal} \mathrm{mol}^{-1}$, may be attributed to the allylic resonance energy affecting the rate-determining step. This is comparable to the generally accepted value. ${ }^{20}$ Since the full significance of the allylic resonance energy is manifested, the transition state is like the initial cleavage products.

Acknowledgments. Financial assistance from the National Research Council of Canada and helpful discussions with Professor D. Darwish are gratefully acknowledged.

(18) B. H. Al-Sader and R, J. Crawford, Can.J. Chem., 46, 3301 (1968).

(19) H. S. Sandhu, J. Phys. Chem., 72, 1857 (1968); W. D. Clark, Ph.D. Dissertation, University of Oregon, Eugene, Ore, 1959.

(20) K. W. Egger, D. M. Golden, and S. W. Benson, J. Amer. Chem. Soc., 86, 5420 (1964); R. J. Ellis and H. M. Frey, J. Chem. Soc., 959 (1964); G. S. Hammond and C. H. Deboer, J. Amer. Chem. Soc., 86, 899 (1964): J. A. Berson and E. J. Walsh, Jr., ibid, 90, 4730 (1968); E. K. Besfield and K. J. Ivin, Trans. Faraday Soc., 571044 (1961); D. M. Golden, N. A. Gac, and S. W. Benson, J. Amer. Chem. Soc., 91, 2136 (1969); D. M. Golden, A. S. Rodgers, and S. W. Benson, ibid., 88, 3196 (1966).

Kunihiko Takagi, Robert J. Crawford* Department of Chemistry, University of Alberta Edmonton, Alberta, Canada Received July 10, 1971

\section{Photochemical Redox Decomposition of} Aqueous Azidopentaamminechromium(III)

Sir:

While photochemical substitution reactions of $\mathrm{Cr}$ (III) coordination compounds are quite common, ${ }^{1,2}$ photochemical redox decompositions of $\mathrm{Cr}$ (III) complexes have not been observed before. ${ }^{3}$ The results of the present investigation suggest that irradiation of aqueous $\mathrm{Cr}\left(\mathrm{NH}_{3}\right)_{5} \mathrm{~N}_{3}{ }^{2+}$ at $\mathrm{pH} 1$ in the charge-transfer (ligand to metal) band leads to redox decomposition of quantum yields 0.45 at $313 \mathrm{~m} \mu$ and 0.4 at $263 \mathrm{~m} \mu$, whereas irradiation at longer wavelengths in the ligandfield bands leads to photoaquation yielding $\mathrm{Cr}\left(\mathrm{NH}_{3}\right)_{4^{-}}$ $\left(\mathrm{H}_{2} \mathrm{O}\right)\left(\mathrm{N}_{3}\right)^{2+}$.

Preliminary investigations as well as older observations ${ }^{4}$ indicate that the $\mathrm{Cr}-\mathrm{N}$ bond in $\mathrm{Cr}\left(\mathrm{NH}_{3}\right)_{5} \mathrm{~N}_{3}{ }^{2+}$ is remarkably stable with regard to thermal substitution reactions. Contrary to other acidopentaamminechromium complexes, where, in thermal reactions preferentially the acido group is being substituted, ${ }^{5} \mathrm{Cr}$ $\left(\mathrm{NH}_{3}\right)_{5} \mathrm{~N}_{3}{ }^{2+}$ seems to show only ammonia aquation.

(1) A. W. Adamson, W, L. Waltz, E. Zinato, D. W. Watts, P. D. Fleischauer, and R. D. Lindholm, Chem. Rev., 68, 541 (1968).

(2) V. Balzani and V. Carassiti, "Photochemistry of Coordination Compounds," Academic Press, New York, N. Y., 1970.

(3) For chromium oxalate complexes, some authors reported photoredox decomposition; other investigators could not confirm these results. For a detailed discussion, see ref 1 and 2.

(4) M. Linhard and W. Berthold, Z. Anorg. Allg. Chem., 278, 173 (1955).

(5) F. Basolo and R. G. Pearson, "Mechanisms of Inorganic Reactions," Wiley, New York, N, Y, 1967.
The photosensivity of $\mathrm{Cr}\left(\mathrm{NH}_{3}\right)_{5} \mathrm{~N}_{3}{ }^{2+}$ was first reported by Linhard and Berthold. 4 Upon irradiation, they observed that the red color of an acidified solution of this complex turned to violet. This color change was accompanied by an increase of $\mathrm{pH}$ and formation of ammonium ions. Release of $\mathrm{N}_{3}-$ was negligible.

We could confirm these observations if the wavelength of irradiation was restricted to the region of the ligand-field bands (maxima and extinction coefficients of the first two ligand-field bands: $\mathrm{L}_{1} 498 \mathrm{~m} \mu, \epsilon 144$; $\mathrm{L}_{2} 382 \mathrm{~m} \mu, \epsilon$ 93). ${ }^{6}$ The irradiated violet solution was treated with concentrated perchloric acid to precipitate an excess of the starting complex. The filtrate exhibited new absorption maxima at 515 and $393 \mathrm{~m} \mu$. Since only ammonia was released, we conclude that $\mathrm{Cr}\left(\mathrm{NH}_{3}\right)_{4}$ $\left(\mathrm{H}_{2} \mathrm{O}\right) \mathrm{N}_{3}{ }^{2+}$ was formed in the photoreaction. It could not yet be decided whether $\mathrm{Cr}\left(\mathrm{NH}_{3}\right)_{4}\left(\mathrm{H}_{2} \mathrm{O}\right) \mathrm{N}_{3}{ }^{2+}$ was formed as the trans or cis isomer.

Irradiation of $\mathrm{Cr}\left(\mathrm{NH}_{3}\right)_{5} \mathrm{~N}_{3}{ }^{2+}$ in $0.1 M \mathrm{HClO}_{4}$ at shorter wavelengths in the CTLM band (maximum at $263 \mathrm{~m} \mu$ with $\epsilon$ 5000) ${ }^{6}$ caused immediate evolution of nitrogen. Simultaneously, the red solution was bleaching and the $\mathrm{pH}$ was increasing. Ammonium was detected, but release of azide was negligible. Azide determinations were made by separation of $\mathrm{N}_{3}^{-}$by an ion-exchange technique and formation of an $\mathrm{Fe}^{3+}-\mathrm{N}_{3}$ complex which was determined spectrophotometrically at $460 \mathrm{~m} \mu, \epsilon 3.68 \times 10^{3} .^{7}$ After continued irradiation, the solution of $\mathrm{Cr}\left(\mathrm{NH}_{3}\right)_{5} \mathrm{~N}_{3}{ }^{2+}$ changed its color from red to a pale green. The photochemical reaction was followed spectrophotometrically. At all wavelengths, the optical density decreased except at the minimum at $435 \mathrm{~m} \mu$ where a slight increase was observed. Two clear isosbestic points at 410 and $442 \mathrm{~m} \mu$ exclude the formation of an intermediate species which could complicate the reaction by secondary photolysis. The decrease of the first ligand-field band at $498 \mathrm{~m} \mu$ was proportional to the absorbed light intensity at least up to a reaction amount of $40 \%$. Hence the photochemical reaction follows a first-order kinetics. After photolysis to completion, the pale green solution had a new maximum at $423 \mathrm{~m} \mu$ with $\epsilon 64$ per chromium.

Quantum yield determinations for disappearance of $\mathrm{Cr}\left(\mathrm{NH}_{3}\right)_{5} \mathrm{~N}_{3}{ }^{2+}$ were made by measuring the decrease of optical density at the maximum of the first ligandfield band at $498 \mathrm{~m} \mu$, taking into account that the optical density at $498 \mathrm{~m} \mu$ drops to a few per cent when the solution is photolyzed to completion. $\mathrm{K}_{3} \mathrm{Fe}\left(\mathrm{C}_{2} \mathrm{O}_{4}\right)_{3}$ actinometry was used. ${ }^{8}$ At a $313-\mathrm{m} \mu$ irradiating wavelength (Osram high-pressure mercury lamp, $100 \mathrm{~W}$; Schott filter No. 313), the quantum yield was 0.45 ; at $263 \mathrm{~m} \mu$ (Hanovia xenon lamp, $150 \mathrm{~W}$; Aminco monochromator), the quantum yield was 0.4. The volume of evolved nitrogen was measured and compared with the decrease of optical density at $498 \mathrm{~m} \mu$. Assuming that $1.5 \mathrm{~mol}$ of $\mathrm{N}_{2}$ was formed per mole of chromium, about $90 \%$ of the required amount of nitrogen was recovered. These observations suggest that a redox decomposition occurs upon irradiation of $\mathrm{Cr}\left(\mathrm{NH}_{3}\right)_{5^{-}}$ $\mathrm{N}_{3}{ }^{2+}$ in the CTLM band according to

$$
\mathrm{Cr}\left(\mathrm{NH}_{3}\right)_{5} \mathrm{~N}_{3}{ }^{2+} \longrightarrow \mathrm{Cr}\left(\mathrm{NH}_{3}\right)_{5}{ }^{2+}+\mathrm{N}_{3}
$$

(6) M. Linhard, H. Siebert, and M. Weigel, Z. Anorg. Allg. Chem., 278, 287 (1955).

(7) E. K. Dukes and R. M. Wallace, Anal. Chem., 33, 242 (1961).

(8) C. G. Hatchard and C. A. Parker, Proc. Roy. Soc., Ser. A, 235, 518 (1956). 
The azide radical yields nitrogen. The other intermediate, $\mathrm{Cr}\left(\mathrm{NH}_{3}\right)_{5}{ }^{2+}$, is very labile and decomposes to give $\mathrm{Cr}$ (II) and ammonia. ${ }^{5}$

The fate of $\mathrm{Cr}$ (II) is not known because the photolyzed pale green solution has not yet been identified. However, we assume that $\mathrm{Cr}$ (II) is oxidized by air to binuclear complexes. Such reactions are typical for the oxidation of $\mathrm{Cr}(\mathrm{II})$ by air in acidic solution. ${ }^{9}$

Strong support for the intermediate formation of $\mathrm{Cr}$ (II) is given by another experiment. If the redox photolysis of $\mathrm{Cr}\left(\mathrm{NH}_{3}\right)_{5} \mathrm{~N}_{3}{ }^{2+}$ in a slightly acidic medium at $320 \mathrm{~m} \mu$ is carried out in the presence of $\mathrm{Co}\left(\mathrm{NH}_{3}\right)_{5}$ $\mathrm{H}_{2} \mathrm{O}^{3+}$, which is not photosensitive under these conditions, extensive formation of $\mathrm{Co}$ (II) does occur. $\mathrm{Cr}$ (II) is known to reduce $\mathrm{Co}\left(\mathrm{NH}_{3}\right)_{5} \mathrm{H}_{2} \mathrm{O}^{3+} \cdot{ }^{10}$

The occurrence of a photoredox decomposition of $\mathrm{Cr}\left(\mathrm{NH}_{3}\right)_{5} \mathrm{~N}_{3}{ }^{2+}$ upon irradiation in the $\mathrm{CT}$ band may be connected to the observation that $\mathrm{Cr}\left(\mathrm{NH}_{3}\right)_{5} \mathrm{Cl}^{2+11}$ and $\mathrm{Cr}\left(\mathrm{NH}_{3}\right)_{5} \mathrm{Br}^{2+}{ }^{12}$ show a large increase of halide aquation upon irradiation in the CT band. Both observations are consistent with a cage mechanism which was first proposed for the photochemical redox reactions of $\mathrm{Co}$ (III) complexes. ${ }^{13.14}$ The absence of azide aquation for $\mathrm{Cr}\left(\mathrm{NH}_{3}\right)_{5} \mathrm{~N}_{3}{ }^{2+}$ upon irradiation in the CT region could be explained by the exceptional short lifetime of the azide radical. ${ }^{15,16}$ After homolytic splitting of the $\mathrm{Cr}^{3+}-\mathrm{N}_{3}$ bond, the azide radical may react fast enough to yield nitrogen before a charge recombination $\mathrm{Cr}^{2+} \ldots \mathrm{N}_{3} \nrightarrow \rightarrow \mathrm{Cr}^{3+} \mathrm{N}_{3}{ }^{-}$can take place.

(9) M. Ardon and R. A. Plane, J. Amer. Chem. Soc, 81, 3197 (1959).

(10) A. Zwickel and H. Taube, ibid., 81, 1288 (1959); J. P. Candlin, J. Halpern, and D. L. Trimm, ibid., 86, 1019 (1964).

(11) H. F. Wasgestian and H. L. Schläfer, Z. Phys. Chem. (Frankfurt am Main), 62, 127 (1968).

(12) P. Riccieri and H. L. Schläfer, Inorg. Chem., 9, 727 (1970).

(13) A. W. Adamson and A. H. Sporer, J. Amer. Chem. Soc., 80, 3865 (1958)

(14) A. Vogler and A. W. Adamson, J. Phys. Chem., 74, 67 (1970).

(15) S. A. Penkett and A. W. Adamson, J. Amer. Chem. Soc., 87, 2514 (1965)

(16) A. Treinin and E. Hayon, J. Chem. Phys., 50, 538 (1969).

$$
\begin{array}{r}
\text { Arnd Vogler } \\
\text { Fachbereich Chemie, Universität Regensburg } \\
8400 \text { Regensburg, Germany }
\end{array}
$$
Received July 6, 1971

\section{Tris[3-(trifluoromethylhydroxymethylene)- $d$ - camphorato]europium(III). A Chiral Shift Reagent for Direct Determination of Enantiomeric Compositions ${ }^{1}$}

Sir:

We wish to report an $\mathrm{nmr}$ method for direct determination of enantiomeric compositions (optical purities) which we have applied successfully to several types of compounds including alcohols, ketones, esters, epoxides, and amines. This method involves use of a new chiral nmr shift reagent, tris[3-(trifluoromethylhydroxymethylene)- $d$-camphorato]europium(III) (1). Similar methods based on chemical-shift nonequivalence of enantiomers (in chiral solvents ${ }^{2}$ or in the presence of a chiral shift reagent, tris[3-(tert-butylhydroxymethylene)- $d$-camphorato]europium(III) $\left.(2)^{3}\right)$ have been re-

(1) Supported by the Research Committee of the Graduate School of the University of Wisconsin.

(2) W. H. Pirkle and S. D. Beare, J. Amer. Chem. Soc., 91, 5150 (1969); W. H. Pirkle, R. L. Muntz, and I. C. Paul, ibid., 93, 2817 (1971)

(3) G. M. Whitesides and D. W. Lewis, ibid., 92, 6979 (1970).
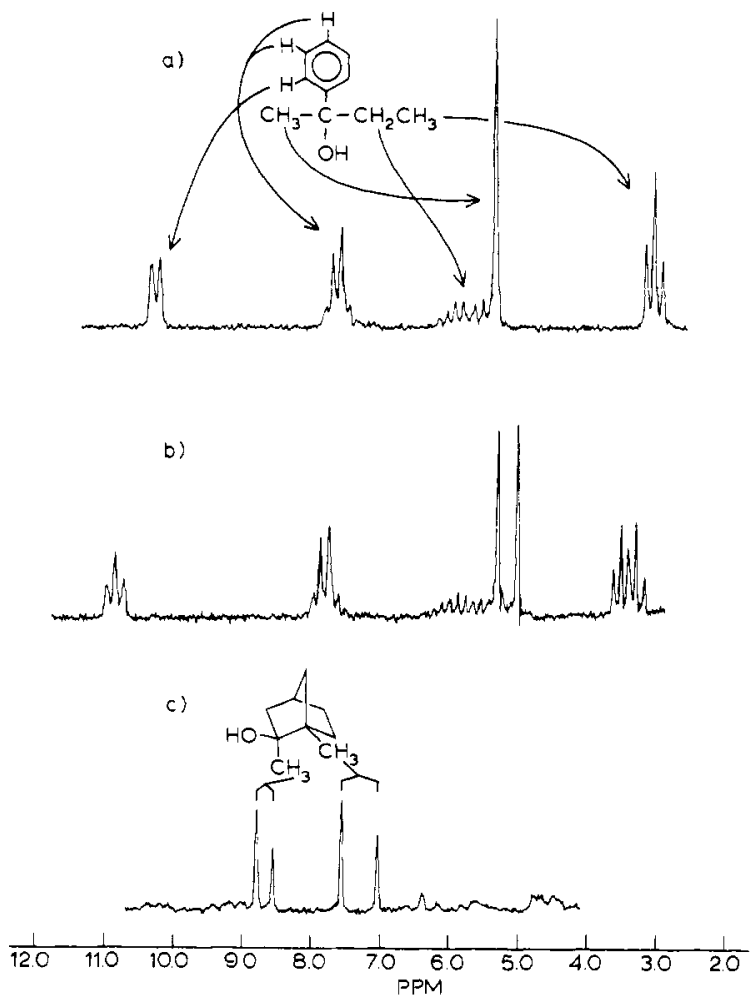

Figure 1. Spectra of $0.54 M$ 2-phenyl-2-butanol in $\mathrm{CCl}_{4}$ in (a) the presence of $0.13 M$ tris(dipivalomethanato)europium(III) and (b) $0.42 M 1$, and (c) spectrum of $0.3 M 1,2$-dimethyl-exo-2-norbornanol in the presence of $0.42 M 1$.

ported. However, these appear to be of limited applicability. Magnitudes of nonequivalence in chiral solvents are small $(\leq 0.04 \mathrm{ppm})^{2}$ which limits the usefulness of this technique for determining enantiomeric compositions. Large pseudocontact-shift differences for enantiomeric amines are observed with $2{ }^{3}$ However, with neutral compounds magnitudes of nonequivalence are generally too small to be useful. On the other hand, with 1 we have observed pseudocontact shift differences for enantiomeric alcohols of $>0.5$ ppm. Moreover, there is very little line broadening and in most cases we have achieved complete resolution of signals for enantiotopic ${ }^{4}$ protons with a $60-\mathrm{MHz}$ instrument.

Compound 1 was prepared by reaction of 3-trifluoromethylhydroxymethylene-d-camphor (3) with europium(III) chloride in the presence of base. ${ }^{5}$ The chelate is an amorphous solid that softens at $100^{\circ}$ and is very soluble in nonpolar solvents. The nmr spectrum of $\mathbf{1}$ ranges from +3 to $-1 \mathrm{ppm}$ from TMS. Compound 3 was obtained by condensation ${ }^{6}$ of $d$-camphor with ethyl trifluoroacetate. Anal. Calcd for $\mathrm{C}_{12} \mathrm{H}_{15} \mathrm{~F}_{3} \mathrm{O}_{2}$ : C, 58.06; H, 6.09. Found: C, 58.17; H, 6.09.

Parts a and $b$ of Figure $1^{7}$ show spectra of carbon tetrachloride solutions of $d l-2$-phenyl-2-butanol (4) in

(4) M. Raban and K. Mislow, Top. Stereochem., 1, 1 (1967).

(5) K. J. Eisentraut and R. E. Sievers, J. Amer. Chem. Soc., 87, 5254 (1965). The chelate was isolated by precipitation (as a resin) by addition of water and extraction into pentane. After extraction with water the dried pentane solution was concentrated to dryness and the residual 1 was dehydrated under vacuum. This material gave the same results as a sample purified by distillation $(0.06 \mathrm{~mm})$. Anal. Calcd for $\mathrm{C}_{36} \mathrm{H}_{42} \mathrm{~F}_{9} \mathrm{O}_{6} \mathrm{Eu}$ : $\mathrm{C}, 48.38 ; \mathrm{H}, 4.74$. Found: $\mathrm{C}, 48.60 ; \mathrm{H}, 4.72$.

(6) K. R. Kopecky, D. Nonhebel, G. Morris, and G. S. Hammond, J. Org. Chem., 27, 1036 (1962).

(7) Spectra were determined with a Varian A-60 spectrometer. 